\title{
RECUPERAÇÃO DE COBRE ATRAVÉS DE SUCATA ELETRÔNICA*
}

Loyslene Rabelo Fernandes ${ }^{1}$

\section{Resumo}

Esse trabalho experimental apresenta os resultados preliminares da lixiviação de placas de circuito eletrônico de microcomputadores sucatados visando a extração de cobre, além da recuperação daquelas espécies através de precipitação por neutralização do licor de lixiviação. As placas foram desmontadas, fragmentadas em pedaços menores, onde passaram por uma incineração no forno mufla, moídas por moagem manual, onde depois sofreram ataque com ácido clorídrico e ácido sulfúrico. Também houve o processo de eletrodeposição com as laminas de cobre encontradas na moagem manual, onde apresentou $14 \%$ de cobre depositado.

Palavras-chave: Reciclagem, Metais, Eletrônicos.

\section{Abstract}

\section{RECOVERY OF COPPER BY ELETRONIC SCRAP}

This experimental work presents the preliminary results of the leaching of electronic circuit boards from scrap microcomputers aimed at the extraction of copper, besides the recovery of those species through precipitation by neutralization of the leaching liquor. The plates were disassembled, fragmented into smaller pieces, where they were incinerated in the muffle oven, ground by manual grinding, where they were then attacked with hydrochloric acid and sulfuric acid. There was also the process of electrodeposition with the copper foils found in manual grinding, where it presented $14 \%$ of copper deposited.

Key words: Recycling, Metals, Electronics.

1 Graduanda em Engenharia Metalúrgica, Faculdade de Engenharia de João Monlevade, , CEP: 35930-314 João Monlevade/MG- 


\section{INTRODUÇÃO}

O consumo excessivo por novas tecnologias vem crescendo e com ela vem crescendo proporcionalmente o volume de lixo eletrônico criado pela sociedade. Os equipamentos eletrônicos se tornam obsoletos e com isso seu de uso se torna limitado. Por consequência, esse volume de sucata eletrônica descartado é normalmente de forma incorreta, podem ocasionar inúmeros problemas, tanto para o meio ambiente e tanto para a saúde dos seres humanos. O meio mais indicado para o tratamento dessa sucata eletrônica seria a reciclagem, mesmo porque a sucata eletrônica pode conter metais de elevado valor comercial, como por exemplo: ouro, prata, platina, estanho e cobre (Barakat, 1998; 1999; Lee et al., 2003). Mas mesmo estando no século XXI, no Brasil existe poucas empresas que atuam no ramo de reciclagem, são bem poucas e mesmo assim não são todas que possuem tecnologia apropriada e condições de preservação ambiental. Infelizmente, esse lixo eletrônico acaba sendo despejado em aterros sanitários junto com o lixo doméstico, uma vez que esses materiais contêm elementos nocivos ao meio ambiente e para a saúde das pessoas, como dito acima. Para evitar a disposição em aterros, tanto sanitários como industriais, esses equipamentos eletrônicos deveriam ser coletados e processados para reutilização total ou parcial dos seus componentes ou para recuperação de metais e plásticos (Menetti, 1995; 1996a; 1996b; 1996c; Veit et al., 2005; Cui e Forssberg, 2007). Este trabalho apresenta os resultados experimentais da lixiviação do cobre presente na sucata eletrônica oriunda de microcomputadores, empregando soluções de ácido clorídrico e ácido sulfúrico.

\section{MATERIAIS E MÉTODOS}

As placas de circuito eletrônico de microcomputadores utilizadas nos experimentos foram obtidas por doação da loja Oficina do Micro, situada na cidade de João Monlevade - Minas Gerais. Os reagentes químicos empregados nesse trabalho foram ácido sulfúrico e ácido clorídrico. A vidraria empregada foi o cadinho que suporta altas temperaturas, vidro relógio, Béquer e tubos de ensaios. As placas de circuito eletrônico foram desmontadas visando remover as partes não-metálicas. A maioria das partes metálicas encontradas foram removidas com uma faca de cozinha e uma chave de fenda. As placas foram desmontadas, em seguida, foram cortadas com uma faca e um martelo de cozinha e os fragmentos obtidos foram pesados e depois lavados com água e secados naturalmente. A parte não-metálica, removida da amostra, foi armazenada em frascos para posterior descarte apropriado. Os fragmentos foram divido e colocados em 2 cadinhos, pesados em uma balança analítica modelo ATX224 marca SHIMADZU. Em seguida, os cadinhos foram levados ao Forno Mufla, que foi aquecido previamente durante 30 minutos numa temperatura de $800^{\circ} \mathrm{C}$, colocaram os cadinhos dentro do forno e durante um tempo de 10 minutos retirou-se o cadinho 1 e 5 minutos depois retirou-se o cadinho 2, totalizando um tempo do cadinho 2 de 15 minutos. Os cadinhos depois foram colocados no dessecador durante 3 horas para voltar a temperatura ambiente, que logo depois passaram para um processo de moagem manual do resíduo através de um almofariz e um pistilo. Foram retirados as laminas de cobre com uma pinça, e usado um imã para retira-se qualquer fragmento magnético. Que logo depois passou-se por um processo de peneiramento, com uma peneira comum de uso doméstico $(0,6 \mathrm{~mm})$ sendo que o material passante (menor que $0,6 \mathrm{~mm}$ ) e o retido (maior que $0,6 \mathrm{~mm}$ ). Para o ataque ácido foram usados 4 tubos de ensaio, dois tubos 
com amostra do cadinho 1 e outros 2 tubos com amostra do cadinho 2. Cada tubo de ensaio tinha aproximadamente $0,10 \mathrm{~g}$ de resíduo passante e $1 \mathrm{ml}$ de ácido concentrado. Utilizou-se ácido sulfúrico e ácido clorídrico. Para a realização da eletrodeposição foi usado um béquer com capacidade para $50 \mathrm{ml}$, uma fonte de corrente contínua $12 \mathrm{~V}$, uma solução de sulfato de cobre II (10\%) dissolvida em agua deionizada, lâminas de cobre (ânodo) e um eletrodo de cobre (cátodo). A solução final foi obtida com adição de $15 \mathrm{ml}$ de solução de sulfato de cobre II (10\%) e $15 \mathrm{ml}$ de agua deionizada. A solução foi filtrada em um filtro de papel quantitativo.

\section{RESULTADOS E DISCUSSÃO}

O processo de separação mecânica caracterizado em desmanchar, separar em diferentes materiais, assim como reduzir a placa de circuito em partículas menores permitiu detectar a presença de vários tipos de materiais, tais como, metais (alumínio, cobre, ferro), polímeros (componentes plástico), cerâmica (fibra de vidro). Dividiu-se os fragmentos em dois cadinhos. A figura abaixo mostra a placa de circuito em partículas menores:

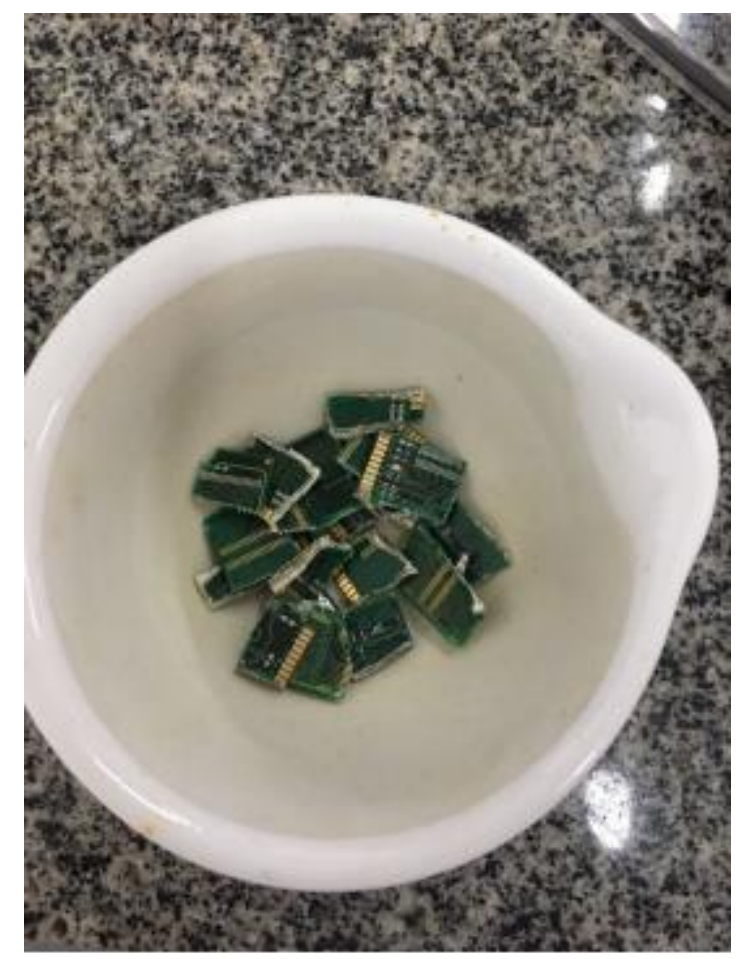

Figura 1. placa de circuito em partículas menores.

No processo de incineração, usando o forno mufla, o cadinho 1 foi deixado por 10 minutos e o cadinho 2 foi deixado por 15 minutos. Durante o processo de incineração, houve uma redução de $29 \%$ do total da amostra da placa de circuito. Do total da massa inicial em comparação com a final, houve uma redução da massa em ambos cadinhos, conforme mostra a tabela a seguir: 


\begin{tabular}{|c|c|c|}
\hline \multicolumn{3}{|c|}{ Redução de massas } \\
\hline & Cadinho 1 & Cadinho 2 \\
\hline Massa Inicial $(\mathrm{g})$ & $3,7536 \mathrm{~g}(100 \%)$ & $3,5313 \mathrm{~g}(100 \%)$ \\
\hline Massa após a Incineração & $2,6359 \mathrm{~g}(71 \%)$ & $2,5092 \mathrm{~g}(71 \%)$ \\
\hline Massa perdida & $1,1177 \mathrm{~g}(29 \%)$ & $1,0221 \mathrm{gg}(29 \%)$ \\
\hline
\end{tabular}

Figura 02. Tabela de Redução de Massas

Tanto no cadinho 1 quanto no cadinho 2 houve uma redução. As amostras após serem incineradas a $800^{\circ} \mathrm{C}$, foram resfriadas lentamente no dessecador até atingir a temperatura ambiente (aproximadamente $25^{\circ} \mathrm{C}$ ). Em seguida, passou- se por um processo de moagem manual, onde o cobre foi retirado com auxílio de uma pinça e foi usado um imã para se retirar qualquer partícula magnética. $O$ material de granulometria menor (passante) foi usado no ataque com ácidos, para identificar a presença de metais existente. É possível visualizar a presença de cobre na figura abaixo:

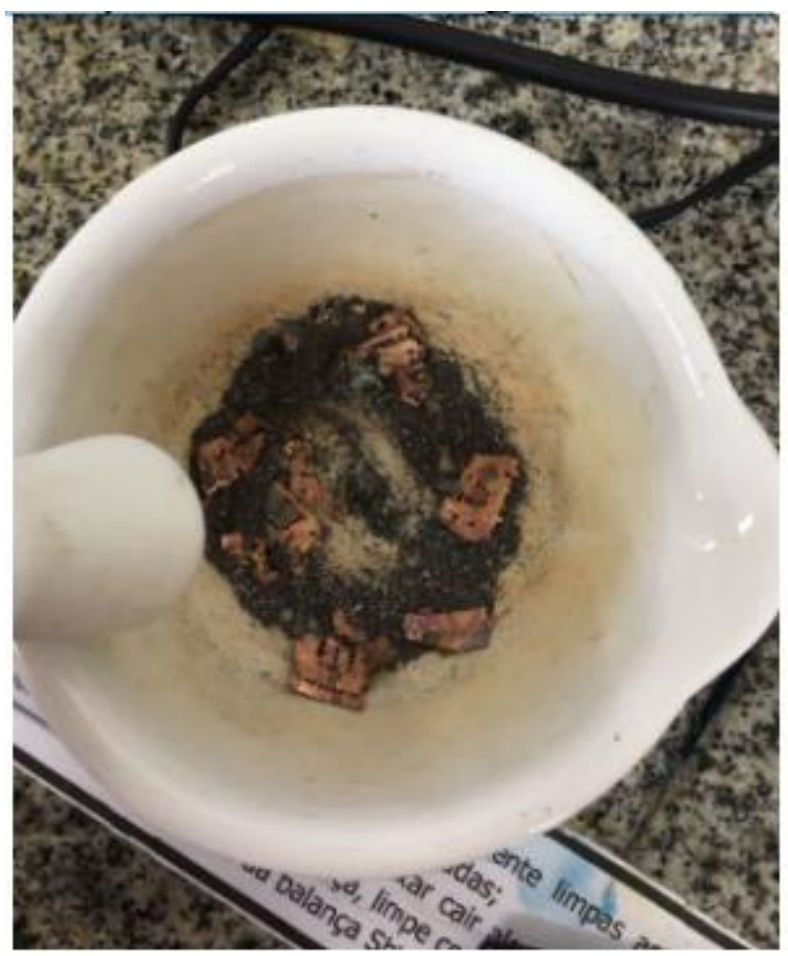

Figura 03. Moagem Manual da sucata após a incineração.

No cadinho 1 foi encontrado cerca de $11 \%$ de cobre, já no cadinho 2 , aproximadamente $6 \%$. Na tabela abaixo, observa-se que a porcentagem de cobre encontrado em ambos cadinhos:

\begin{tabular}{|c|c|c|}
\hline \multicolumn{3}{|c|}{ Porcentagens de Cobre encontrado } \\
\hline & Cadinho 1 & Cadinho 2 \\
\hline Cobre & $0,4266 \mathrm{~g}$ & $0,2056 \mathrm{~g}$ \\
\hline Porcentagem & $11,36 \%$ & $5,82 \%$ \\
\hline
\end{tabular}

Figura 04. Porcentagens de cobre encontrado. 
Foi executado um ataque com 2 tipos de ácidos concentrados para avaliar a reatividade na presença de cobre $(\mathrm{Cu})$.

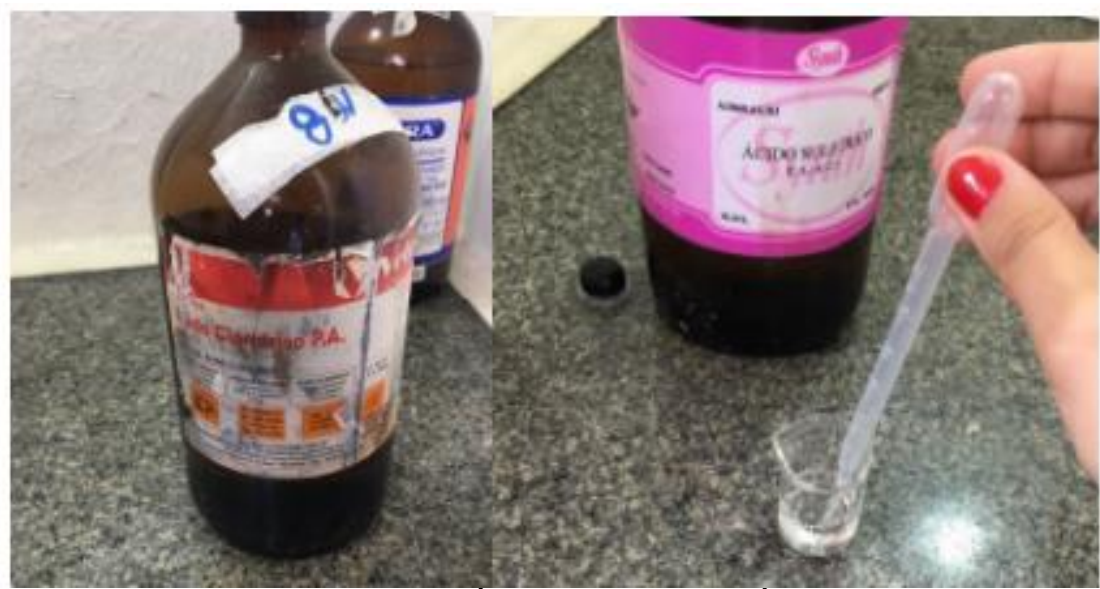

Figura 05. Reagentes (Ácido Clorídrico e Ácido Sulfúrico).

No ataque ácido com ácido sulfúrico apresentou uma solução que permaneceu mais incolor comparada aos outros tubos de ensaio, não houve a liberação de calor, mas é possível observar a presença de um corpo de fundo na parte inferior do tubo.

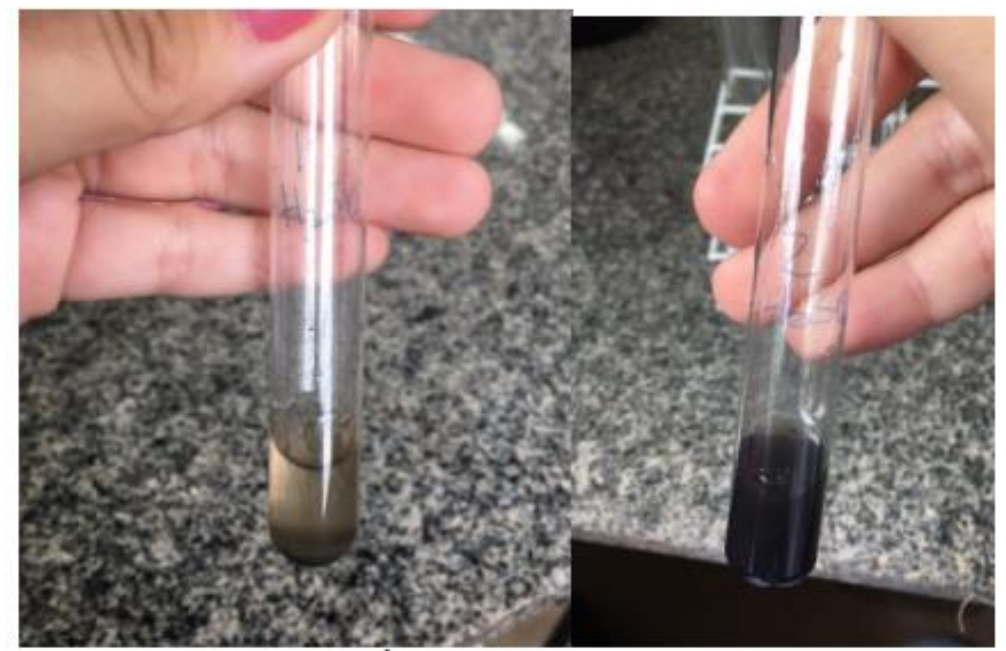

Figura 06. Ataque do Ácido Sulfúrico ( A: cadinho 1// B: cadinho 2).

A maioria dos metais reage com o ácido sulfúrico, com formação de hidrogênio gasoso e sulfato do metal em reação. Já para $\mathrm{Cu}$, a reação só ocorre com ácido concentrado a quente, segundo a equação 1.

$$
\mathrm{Cu}_{(\mathrm{s})}+\mathrm{H}_{2} \mathrm{SO}_{4(\mathrm{aq})} \rightarrow \mathrm{CuSO}_{4(\mathrm{aq})}+\mathrm{H}_{2(\mathrm{~g})} \quad \text { equação } 1
$$

O cobre é mais nobre que alguns metais, ele não reagem com $\mathrm{H} 2 \mathrm{SO} 4$ diluído e nem com o concentrado na temperatura ambiente, portanto não houve liberação de gás. No ataque com ácido clorídrico, a solução ficou com coloração amarela esverdeada, indicando a presença de cobre em ambos os tubos pela formação do íon complexo $\mathrm{CuCl4}-2$ resultante da reação. 
A solução usada na eletrodeposição foi calculada pela massa de CuSO4 para preparar $100 \mathrm{ml}$ de solução numa concentração de 0,1 molar. Foi elaborada com $100 \mathrm{ml}$ de água deionizada mais $1,5661 \mathrm{~g}$ de sulfato de cobre II. Depois retirou $30 \mathrm{ml}$ da solução preparada e colocou num béquer de $50 \mathrm{ml}$. Junto com o eletrodo de cobre (cátodo) e as laminas de cobre (ânodo) foi ligado a fonte de corrente continua onde teve um tempo aproximado de 25 minutos.

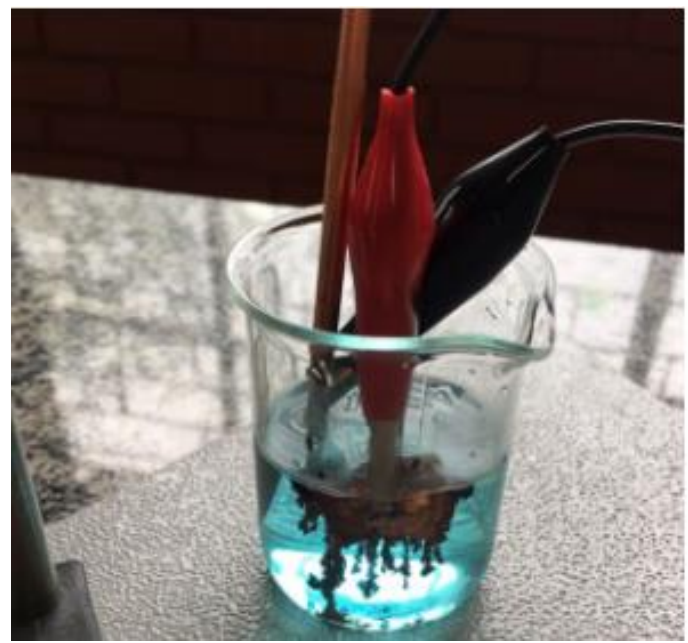

Figura 09. Eletrodeposição.

O material recuperado foi filtrado e depois passou por uma secagem em estufa a $50^{\circ} \mathrm{C}$ em um tempo de 10 horas na estufa.

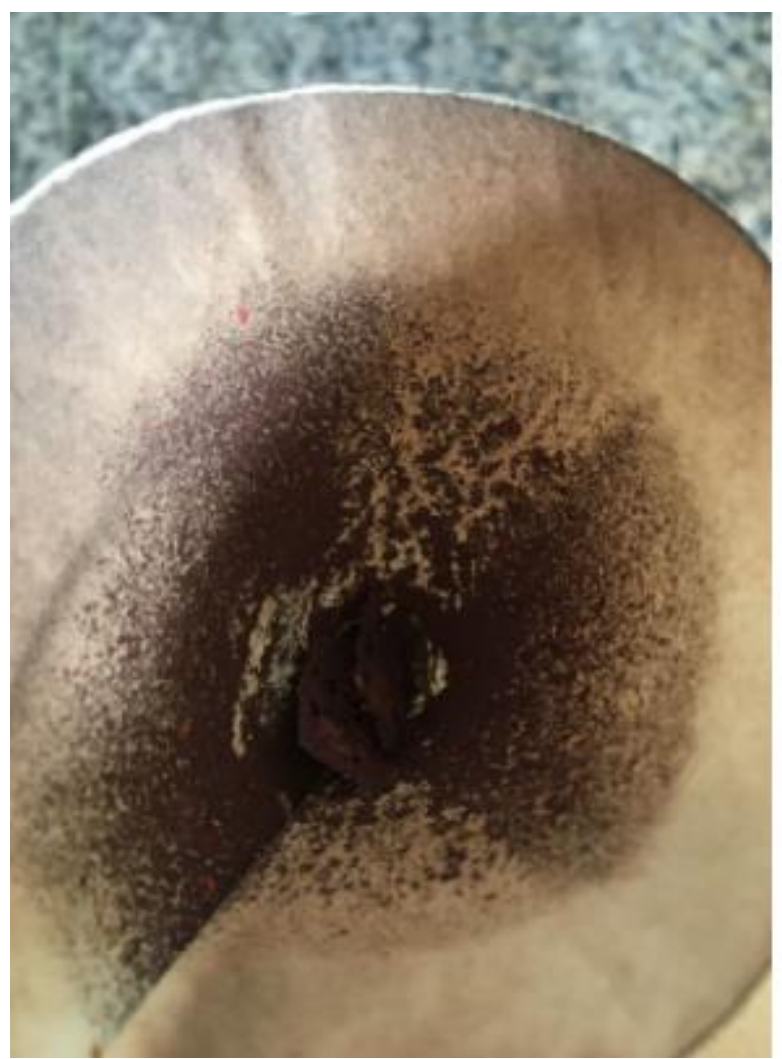

Figura 10. Papel filtrado com cobre recuperado.

A massa inicial do eletrodo era de $0,8965 \mathrm{~g}$, após passar pela secagem, foi medida novamente a massa, que apresentou um aumento de 3\%. Já a placa de cobre 
colocada no ânodo tem uma redução de $83 \%$. O filtro de papel cuja massa inicial era de $1,0724 \mathrm{~g}$ passou para $1,2773 \mathrm{~g}$, com uma massa de $0,1661 \mathrm{~g}$ de $\mathrm{Cu}$ formada, ou seja, apresentou um aumento de $14,44 \%$ resultante do cobre depositado.

\begin{tabular}{|c|c|c|}
\hline \multicolumn{3}{|c|}{ Eletrodeposição do Cu (cobre) } \\
\hline & Massa Inicial (g) & Massa Final (g) \\
\hline Eletrodo & $0,8965 \mathrm{~g}(100 \%)$ & $0,9285 \mathrm{~g}(103 \%)$ \\
\hline Placa de cobre & $0,4266 \mathrm{~g}(100 \%)$ & $0,007252 \mathrm{~g} \mathrm{(17 \% )}$ \\
\hline Filtro de Papel & $1,0724 \mathrm{~g}(100 \%)$ & $1,2273(\mathrm{~g})(114 \%)$ \\
\hline
\end{tabular}

Figura 11. Tabela do Processo de Eletrodeposição do Cobre.

\section{CONCLUSÃo}

O trabalho mostrou que há métodos para a retirada de metais das placas de circuito impresso, através de processamentos mecânicos e metalúrgicos, tais como eletrodeposição, processos pirometalúrgicos e hidrometalúrgicos. Os resíduos resultantes do processamento de moagem e peneiramento podem servir como ferramentas a serem utilizadas em novos estudos e desenvolvimento de pesquisas. Os valores encontrados de cobre nesse trabalho foram satisfatórios. A natureza, ou seja, o meio ambiente encontra-se em desvantagens nesta corrida tecnológica, que teve início na Revolução Industrial. É importante frisar que a preservação ambiental é tão relevante quanto o desenvolvimento tecnológico. Faz-se necessário um maior incentivo para que novas pesquisas sejam realizadas a fim de viabilizar o processo de recuperação das matérias-primas presentes na sucata eletrônica, que são descartadas diariamente nos aterros, causando uma contaminação do solo e dos recursos hídricos. Conclui-se que o trabalho é um grande avanço para o meio ambiente e para as indústrias, uma vez que visa reciclar sucata eletrônica que não se utiliza mais para a recuperação de um metal como o cobre.

\section{Agradecimentos}

Agradeço a Universidade do Estado de Minas Gerais - Unidade João Monlevade pela disponibilização do laboratório e a Professor Fabricia Guedes pela ajuda e conhecimentos passados.

\section{REFERÊNCIAS}

ANUÁRIO MINERAL BRASILEIRO. 2006. Departamento Nacional de Produção Mineral, Ministério da Minas e Energia-Brasil, Brasília, DF, ano XXXV. Acessado em: 23/11/2016, disponível em: http://www.dnpm.gov.br/conteudo.asp? IDSecao=68\&IDPagina=789.

BARAKAT, M. A. 1998. Recovery of lead, tin and indium from alloy wire scrap. Hydrometallurgy, 49:63-73.

MORAES, Viviane T. Recuperação de Metais Através do Processamento Mecânico e Hidrometalurgico Utilizado Placas de Circuito Impresso de Celulares Obsoletos. São Paulo, 2010, disponível em http://www.teses.usp.br/teses/disponiveis/3/3133/tde- 19042011$100037 /$ php, acesso em 23/11/2016. 
RIBEIRO, Pedro P. M. Concentração de Metais Contidos em Placas de Circuito Impresso de Computadores Descartados. Rio de Janeiro, Junho de 2013. Trabalho de conclusão de curso, disponível em http://monografias.poli.ufrj.br/monografias/monopoli1000720 7.pdf, acesso em 23/11/2016.

CORCINI, Tatiana A.; GONZAGA, Emanuelle A. C. Recuperação de Metais a partir de Sucatas Eletrônicas. João Monlevade, agosto de 2015. Trabalho de conclusão de curso.

VEIT, Hugo M. Reciclagem de Cobre de Sucatas de Placas de Circuito Impresso, Porto Alegre, Janeiro de 2005. Dissertação de Doutorado, disponível em http://www.lume.ufrgs.br/handle/10183/3432, acesso dia 23/11/2016.

MENETTI, R.P.; CHAVES, A.P. e TENÓRIO, J.A.S. 1996a. Obtenção de concentrados metálicos não ferrosos apartir de sucata eletrônica. In: $51^{\circ}$ Congresso Anual da ABM , Porto Alegre, RS, 1996. Anais. 4:205- 216.

MENETTI, R.P.; CHAVES, A.P. e TENÓRIO, J.A.S. 1996b. Recuperação de Au e Ag de concentrados obtidos a partir de sucata eletrônica. In: 51ํㅡㄹ Congresso Anual da ABM, Porto Alegre, RS, 1996. Anais... Porto Alegre. 4:217-224 